(Supporting information for ACS Nano)

\title{
Stem Cell-Derived Extracellular Vesicle-Bearing Dermal Filler Ameliorates the Dermis Microenvironment by Supporting CD301b-Expressing Macrophages
}

Dong Gil You ${ }^{1, t}$, Jae Yoon An ${ }^{1, t}$, Wooram Um ${ }^{1}$, Jae Min Jung', Byeong Hoon Oh', Van Quy Nguyen ${ }^{1}$, Jueun Jeon ${ }^{1}$, Jungmi Lee ${ }^{1}$, Dong-Gyu Jo ${ }^{2,3,4}$, Yong Woo Cho ${ }^{4,5}$, and Jae Hyung Park ${ }^{1,2,4, *}$

${ }^{1}$ School of Chemical Engineering, College of Engineering, Sungkyunkwan University, 2066 Seobu-ro, Jangan-gu, Suwon 16419, Republic of Korea

${ }^{2}$ Biomedical Institute for Convergence at SKKU (BICS), Sungkyunkwan University, 2066 Seoburo, Jangan-gu, Suwon 16419, Republic of Korea

${ }^{3}$ School of Pharmacy, Sungkyunkwan University, 2066 Seobu-ro, Jangan-gu, Suwon 16419, Republic of Korea

${ }^{4}$ ExoStemTech Inc., 55 Hanyangdaehak-ro, Sangnok-gu, Ansan 15588, Republic of Korea

${ }^{5}$ Department of Chemical Engineering, Hanyang University, 55 Hanyangdaehak-ro, Sangnok-gu, Ansan 15588, Republic of Korea

*Corresponding author: Jae Hyung Park

School of Chemical Engineering, Sungkyunkwan University, 2066 Seobu-ro, Jangan-gu, Suwon

16419, Republic of Korea

E-mail: jhpark1@skku.edu 


\section{MATERIALS AND METHODS}

Isolation of ADSC-derived EVs. The TFF system was used for ADSC-EV isolation. Briefly, primary human ADSCs at a concentration of $1 \times 10^{6}$ cells per T-175 flask were incubated with $10 \% \mathrm{FBS}$ and $1 \% \mathrm{AA}$-contained RPMI- 1640 at $37^{\circ} \mathrm{C}$ in a humidified $5 \% \mathrm{CO}_{2}$ atmosphere for $3 \mathrm{~d}$. The cells were then washed twice with DPBS, and the medium was replaced with serum-free RPMI-1640. After $24 \mathrm{~h}$ incubation, the conditioned medium was centrifuged at 2,000 $\times \mathrm{g}$ for 20 min, and the supernatant was filtered through a $0.22 \mu \mathrm{m}$ filter (Millipore, MA, USA) to remove cell debris. Following the procedure previously described in published articles, the conditioned medium was concentrated using TFF to obtain EVs. ${ }^{1-2}$ For the fluorescent labeling of EVs, $100 \mu \mathrm{L}$ Flamma 675 NHS ester $(5 \mathrm{mg} / \mathrm{mL})$ was added to $1 \mathrm{~mL} \mathrm{EVs}\left(1.5 \times 10^{10}\right.$ particles $)$ solution and incubated at $4{ }^{\circ} \mathrm{C}$ for $12 \mathrm{~h}$. Then, the solution was purified using a PD-10 desalting column (GE Healthcare, Chicago, USA) to remove excess dye.

Western blotting Analysis. Proteins of the ADSCs and ADSC-EVs were separated via electrophoresis using 10\% sodium dodecyl sulphate polyacrylamide gel electrophoresis (SDSPAGE) gel. As primary antibodies, anti-CD9 antibody (1:500), anti-CD63 antibody (1:500), anticalnexin antibody (1:750), and anti- $\beta$-actin antibody (1:2000) were used. Afterward, the HRPconjugated anti-rabbit $\operatorname{IgG}(1: 1000)$ or HRP-conjugated anti-mouse $\operatorname{IgG}(1: 1000)$ were used as secondary antibodies. In order to analyze type I collagen expression in EVHyal-Gel-treated mice, proteins of the skin tissues were separated via electrophoresis using 6\% SDS-PAGE gel. For GAPDH analysis, 10\% SDS-PAGE gel was used. As primary antibodies, anti-collagen I antibody (1:750) or anti-GAPDH antibody (1:1000) were used. Then, HRP-conjugated anti-rabbit IgG (1:2000) or HRP-conjugated anti-mouse IgG $(1: 1000)$ were used as secondary antibodies. The 
blotted membranes were imaged using a biomolecular imager (LAS-3000; Fuji Photo Film, Japan).

To identify the molecular weights of the protein, we used a protein ladder (Precision Plus Protein Dual Color Standards; BIO-RAD, USA).

miRNA sequencing and data analysis. miRNA sequencing and data analysis. To investigate the miRNA profiles of the EVs, freeze-dried EVs were provided to Macrogen, Inc. (Seoul, Korea). As described previously, ${ }^{3}$ RNA from the EVs was polyadenylated and Illumina adapters were added. After complementary DNA was synthesized, small RNA libraries were constructed using a SMARTer smRNA-Seq Kit for Illumina (Takara Bio, Shiga, Japan) and EV's RNA was integrated using an Agilent Technologies 2100 Bioanalyzer (Santa Clara, CA, USA). Afterward, the libraries were sequenced on an Illumina HiSeq 2500 instrument (Illumina, CA, USA).

\section{REFERENCES}

1. Choi, J. S.; Cho, W. L.; Choi, Y. J.; Kim, J. D.; Park, H. A.; Kim, S. Y.; Park, J. H.; Jo, D. G.; Cho, Y. W., Functional Recovery in Photo-Damaged Human Dermal Fibroblasts by Human Adipose-Derived Stem Cell Extracellular Vesicles. J. Extracell. Vesicles 2019, 8(1), 1565885.

2. Han, H. S.; Lee, H.; You, D.; Nguyen, V. Q.; Song, D. G.; Oh, B. H.; Shin, S.; Choi, J. S.; Kim, J. D.; Pan, C. H.; Jo, D. G.; Cho, Y. W.; Choi, K. Y.; Park, J. H., Human Adipose Stem CellDerived Extracellular Nanovesicles for Treatment of Chronic Liver Fibrosis. J. Control. Release 2020, 320, 328-336.

3. Jung, Y. J.; Kim, H. K.; Cho, Y.; Choi, J. S.; Woo, C. H.; Lee, K. S.; Sul, J. H.; Lee, C. M.; Han, J.; Park, J. H.; Jo, D. G.; Cho, Y. W., Cell Reprogramming Using Extracellular Vesicles from Differentiating Stem Cells into White/Beige Adipocytes. Sci. Adv. 2020, 6(13), eaay6721. 
a

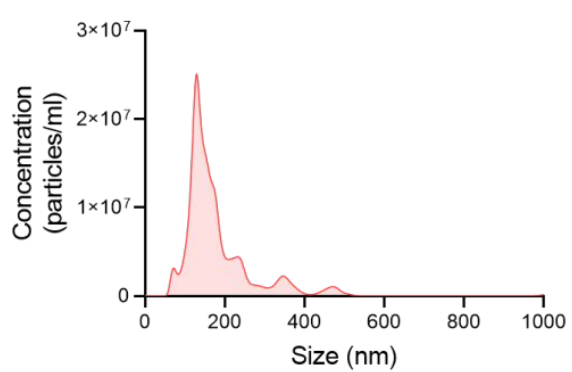

d

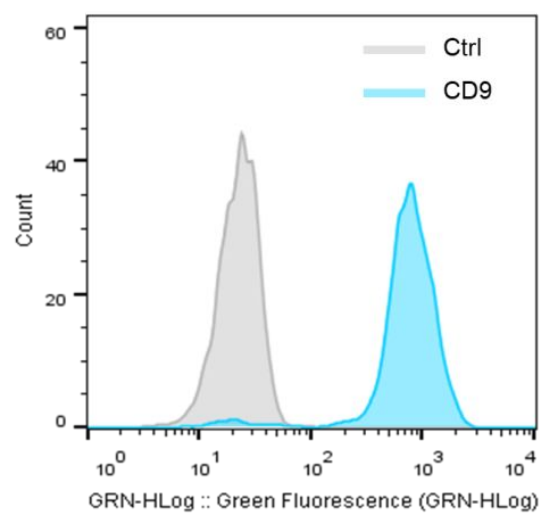

b

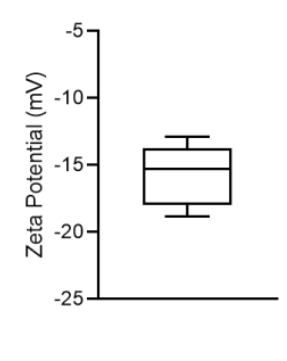

C
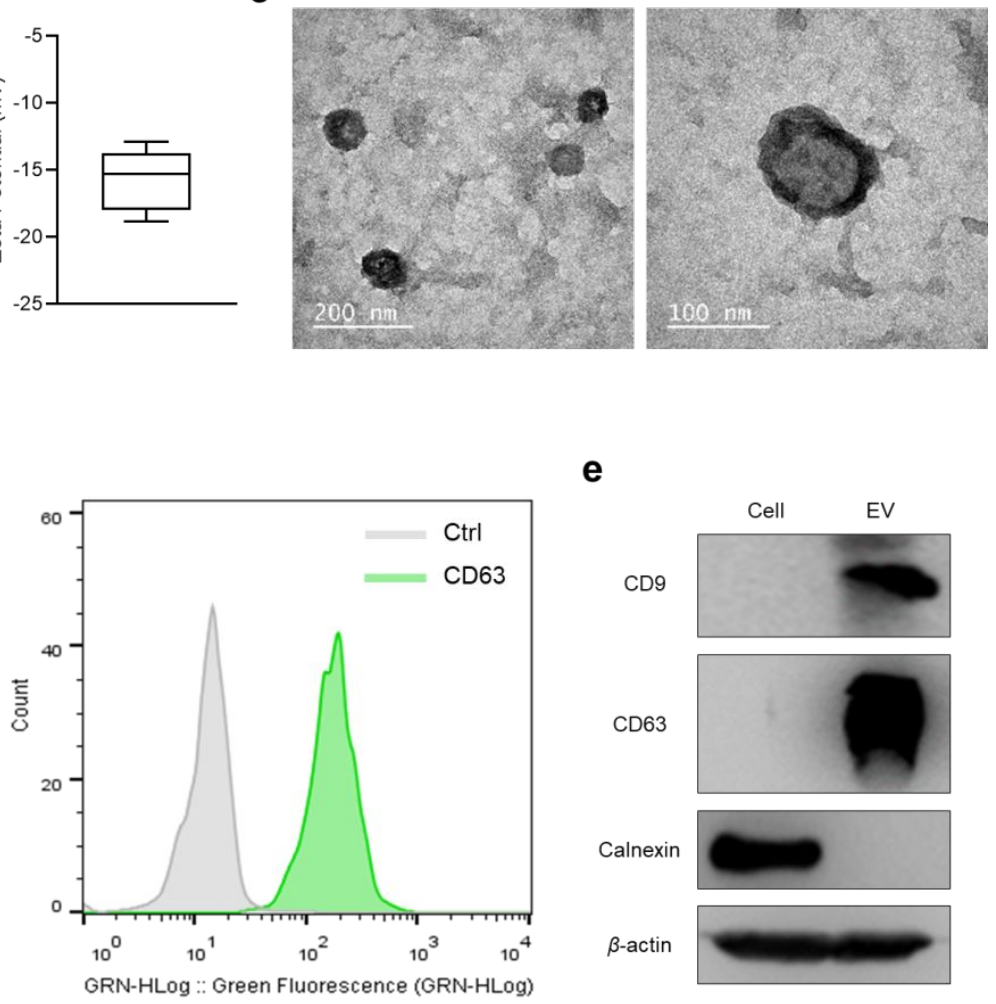

e

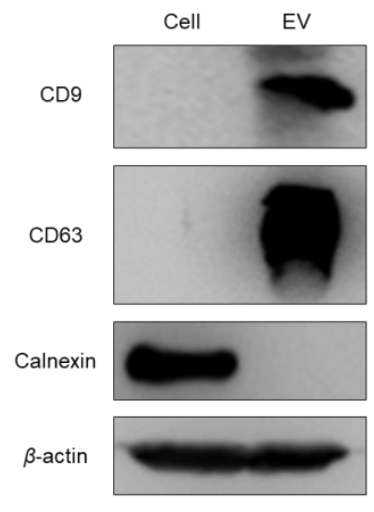

Figure S1. (a) Size distribution of EVs. (b) Zeta potential of EVs. Error bars represent the SD (n $=5$ ). (c) TEM images of the EVs. (d) Flow cytometry analysis of the exosomal surface markers on the EVs. (e) Western blotting analysis of ADSCs and EVs. 


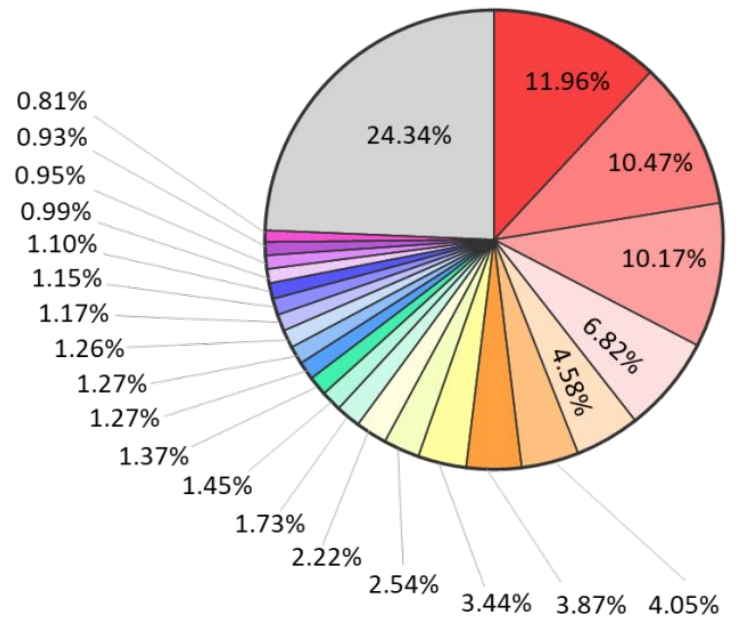

hsa-let-7a-5p hsa-miR-199a-5p

hsa-miR-23a-3p hsa-miR-199a-3p

$\square$ hsa-let-7b-5p $\square$ hsa-miR-199b-3p

$\square$ hsa-miR-24-3p $\square$ hsa-miR-23b-3p

$\square$ hsa-miR-125b-5p $\square$ hsa-miR-221-3p

$\square$ hsa-miR-29a-3p $\square$ hsa-let-7g-5p

hsa-let-7f-5p hsa-miR-196a-5p

$\square$ hsa-miR-21-5p $\square$ hsa-miR-337-3p

$\square$ hsa-miR-222-3p $\square$ hsa-miR-409-3p

$\square$ hsa-miR-574-3p $\square$ hsa-miR-191-5p

$\square$ hsa-miR-125a-5p $\square$ hsa-miR-25-3p

$\square$ hsa-let-7e-5p $\square$ Others

Figure S2. Pie graph shows miRNAs in EVs. 

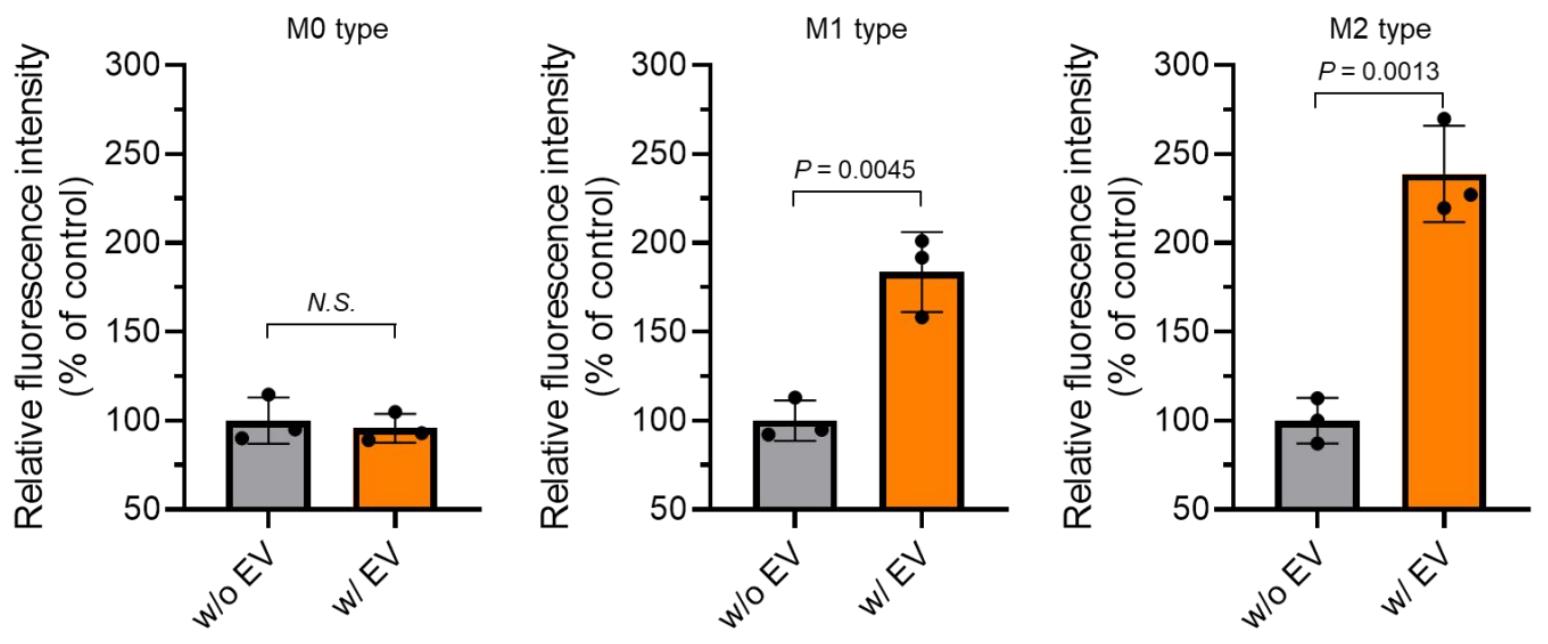

Figure S3. Fluorescence intensity of CD301b expression on RAW264.7 cells by EVs. Error bars represent SD. $P$ values were analyzed by the t-test of variance. 
a

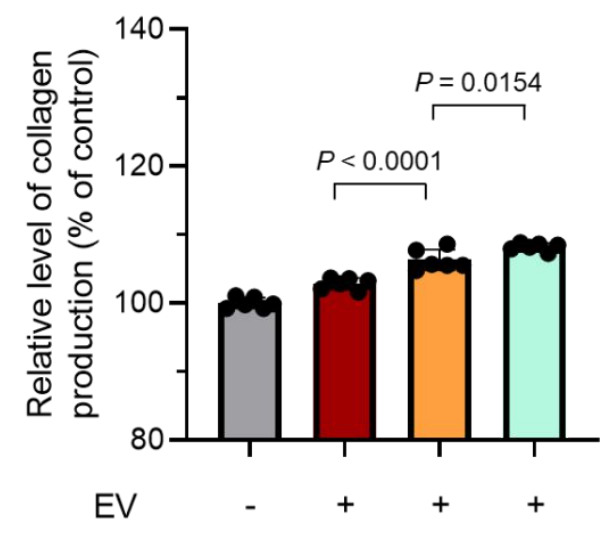

EV dose $\quad-\quad 1 \times 10^{7} \quad 5 \times 10^{7} \quad 1 \times 10^{8}$ pre-treatment

b

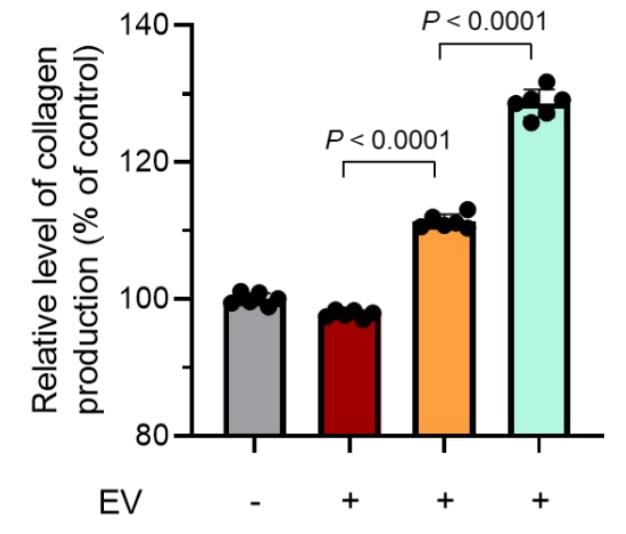

EV dose $\quad-\quad 1 \times 10^{7} \quad 5 \times 10^{7} \quad 1 \times 10^{8}$

$\underset{\text { pre-treatment }}{\text { Macrophage }}+\quad+\quad+\quad+$

Figure S4. (a) Relative collagen production level from NIH/3T3 cells treated with various concentrations of EVs $(n=6)$. (b) Relative collagen production level from NIH/3T3 cells in the co-culture system with RAW264.7 cells pre-treated with various concentrations of EVs $(n=6)$. Error bars represent standard deviation (SD). $P$ values were analyzed by the One-way ANOVA. 
$\mathbf{a}$

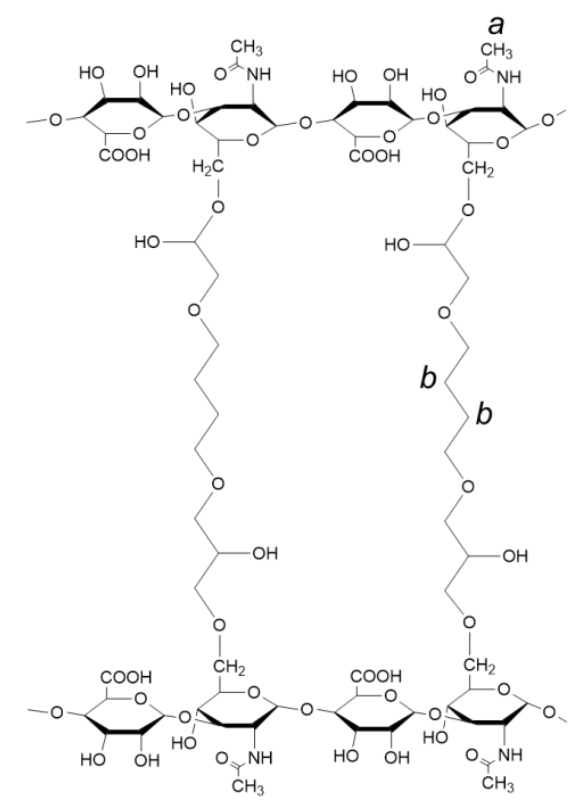

b

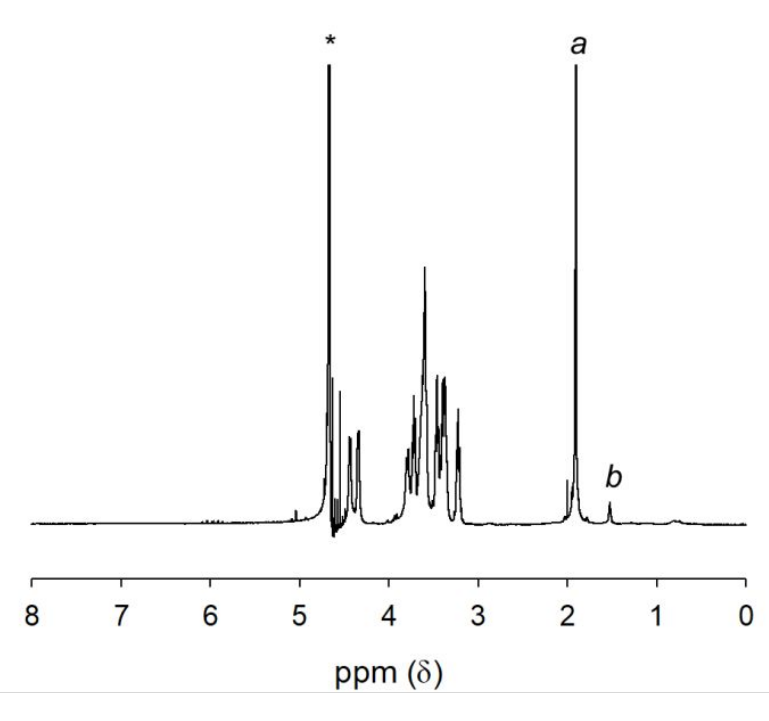

Figure S5. (a) Chemical structure and (b) ${ }^{1} \mathrm{H}$ NMR spectrum of Hyal-BDDE. 
a

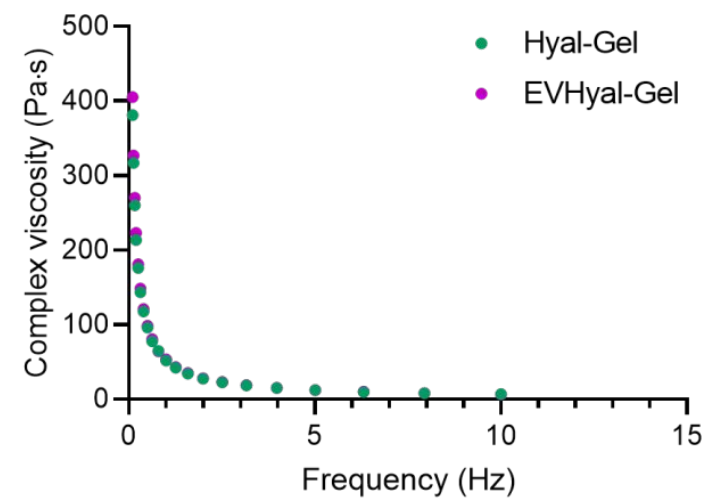

b

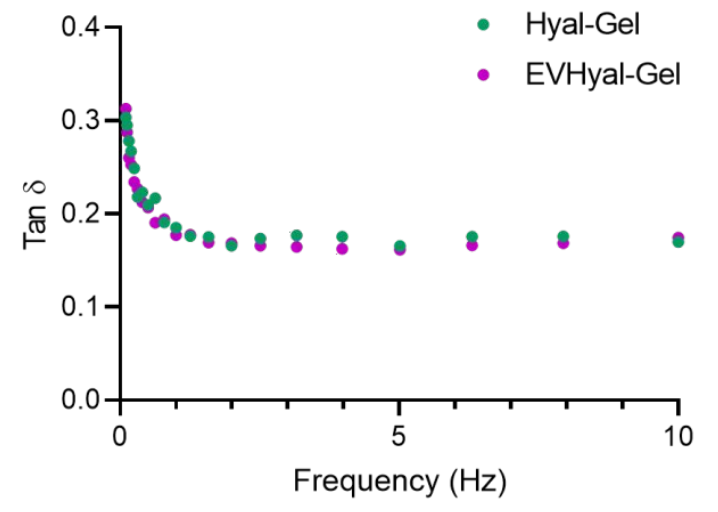

Figure S6. (a) Complex viscosity and (b) Tan $\delta$ of the Hyal-Gels and EVHyal-Gels. 
a

\begin{tabular}{|c|c|c|c|}
\hline Samples & HA amount & BDDE amount & $\begin{array}{c}\text { Degree } \\
\text { of crosslinking }\end{array}$ \\
\hline Hyal-Gel_1 & $5,000 \mathrm{mg}$ & $0 \mu \mathrm{L}(0 \mathrm{mmol})$ & $0 \%$ \\
\hline Hyal-Gel_2 & $5,000 \mathrm{mg}$ & $9.86 \mu \mathrm{L}(0.0536 \mathrm{mmol})$ & $0.89 \%$ \\
\hline Hyal-Gel_3 & $5,000 \mathrm{mg}$ & $49.3 \mu \mathrm{L}(0.2681 \mathrm{mmol})$ & $1.05 \%$ \\
\hline Hyal-Gel_4 & $5,000 \mathrm{mg}$ & $98.6 \mu \mathrm{L}(0.5363 \mathrm{mmol})$ & $4.64 \%$ \\
\hline Hyal-Gel_5 & $5,000 \mathrm{mg}$ & $147.9 \mu \mathrm{L}(0.8044 \mathrm{mmol})$ & $13.1 \%$ \\
\hline Hyal-Gel_6 & $5,000 \mathrm{mg}$ & $197.2 \mu \mathrm{L}(1.0725 \mathrm{mmol})$ & $18.1 \%$ \\
\hline
\end{tabular}

b

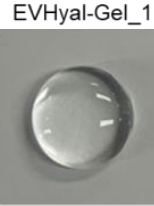

EVHyal-Gel_4
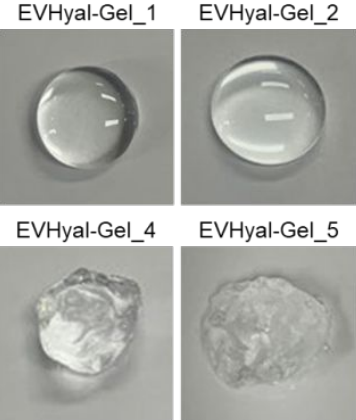

EVHyal-Gel_3

EVHyal-Gel_5

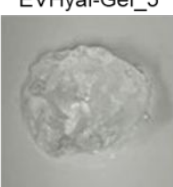

EVHyal-Gel_6

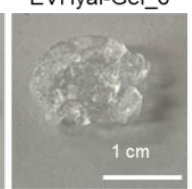

C

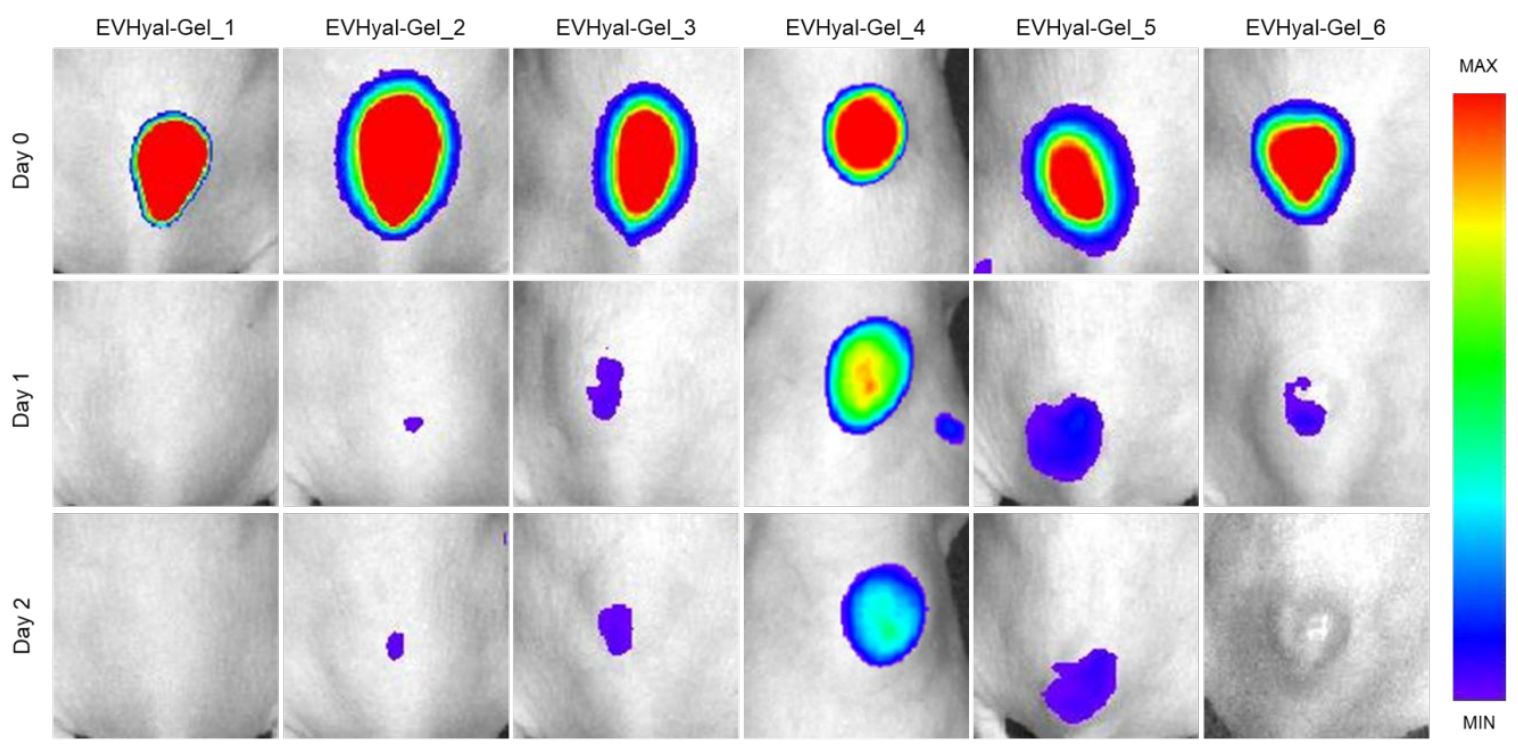

Figure S7. (a) The degree of crosslinking of Hyal-Gels in various BDDE concentrations. (b) Representative images of EVHyal-Gels in various BDDE concentrations. (c) In vivo fluorescence imaging of Flamma 675-labeled EVs from various types of EVHyal-Gels-treated SKH-1 mice. 


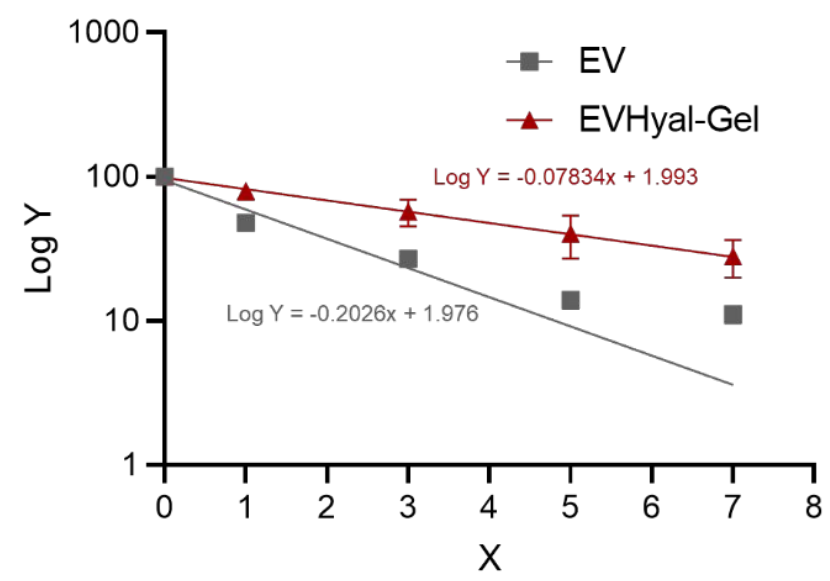

Figure S8. In vivo biological half-lives of the bare EVs and EVHyal-Gels. 


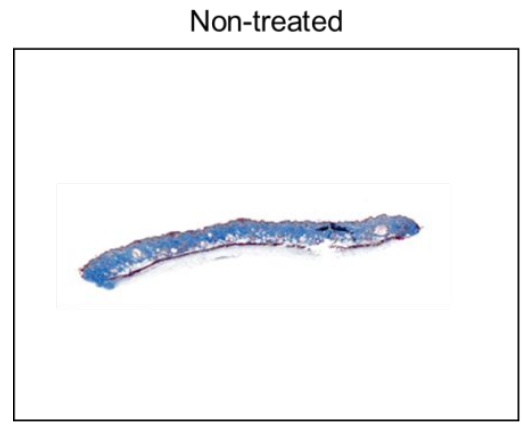

EVHyal-Gel

(1x107/head)
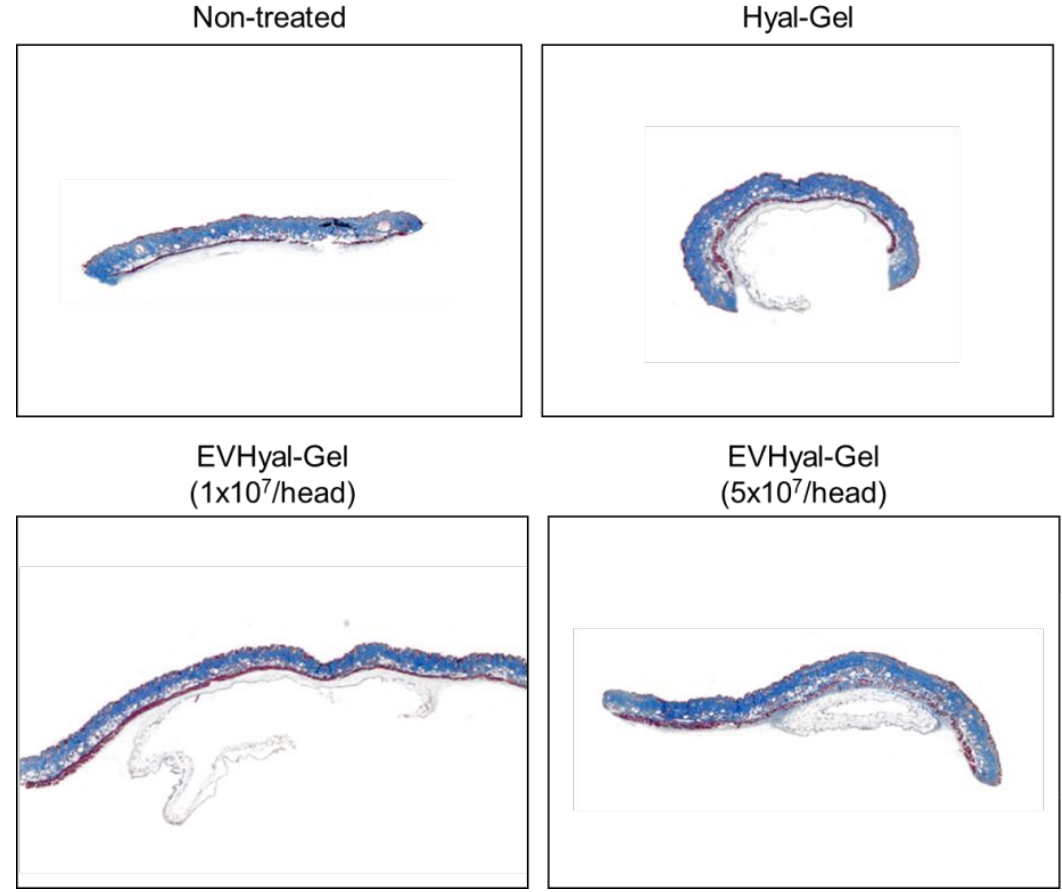

EVHyal-Gel

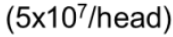
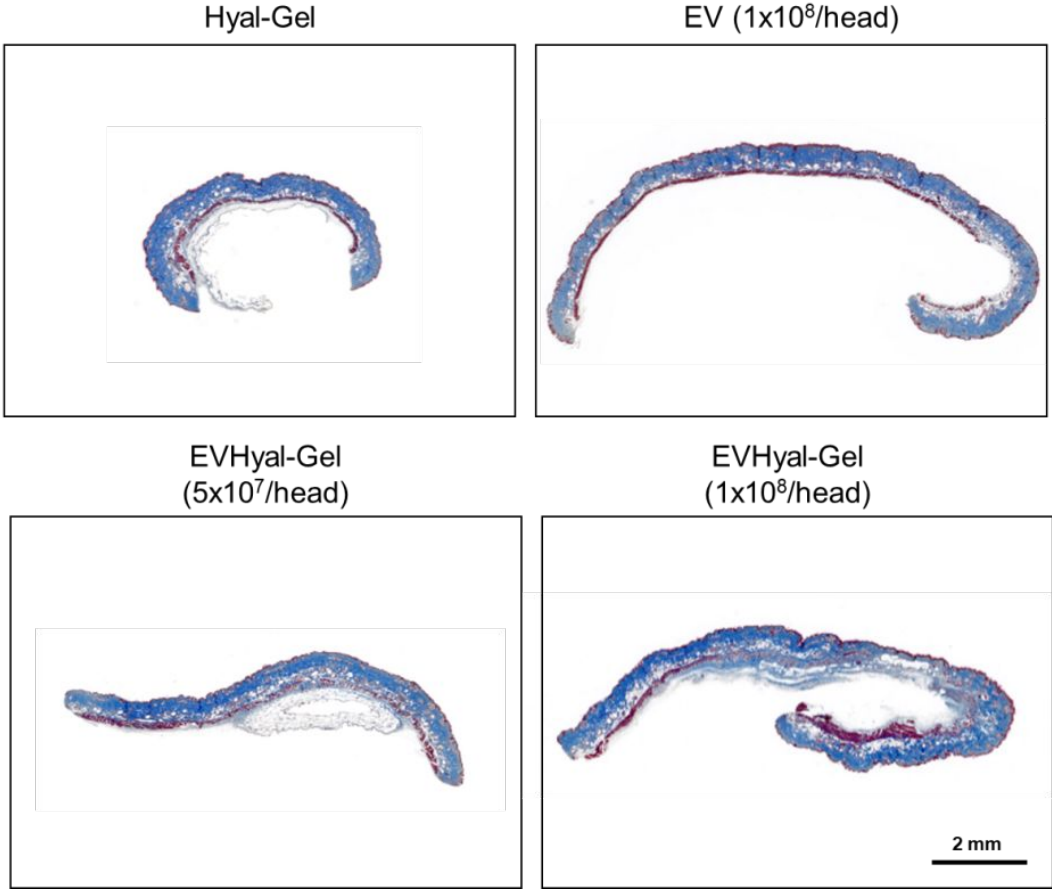

EVHyal-Gel

(1 $\times 10^{8} /$ head)

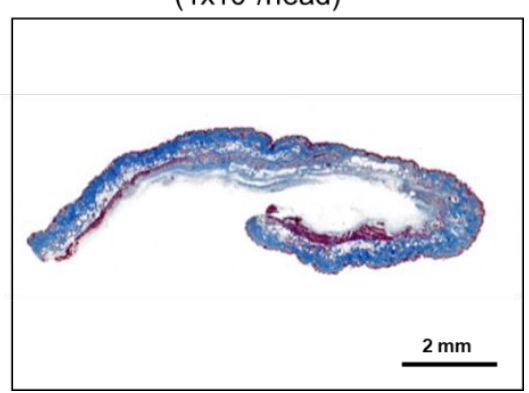

Figure S9. Masson's trichrome staining images of skin layer of SKH-1 mice on 4 weeks after administration. 
a

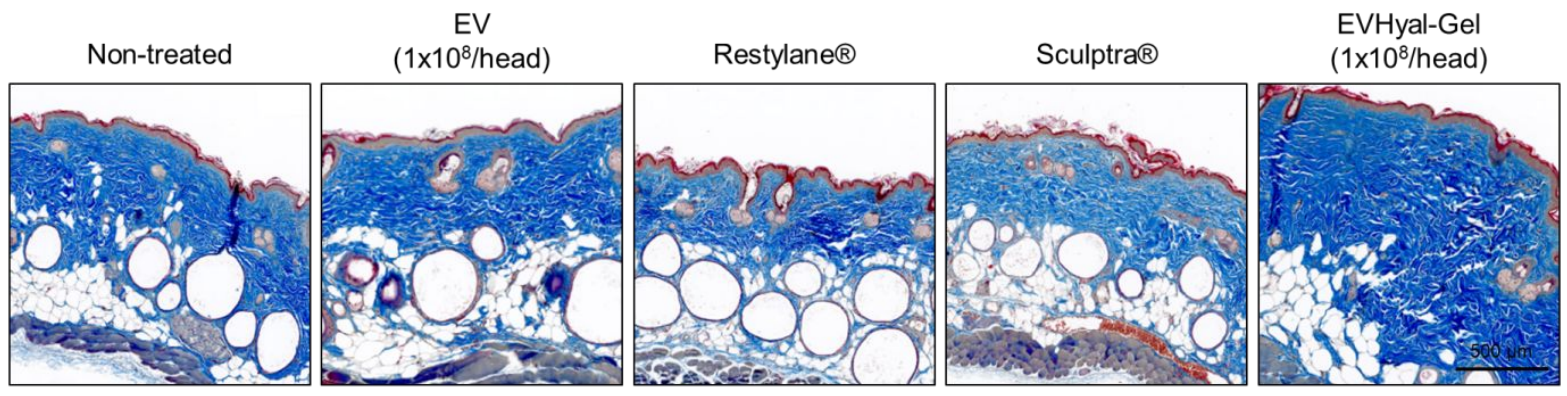

b

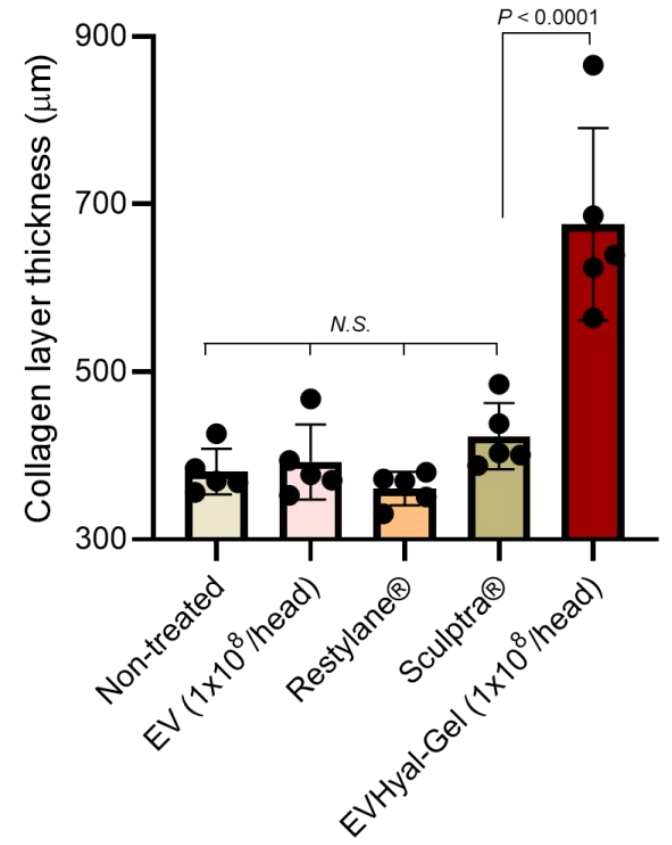

C

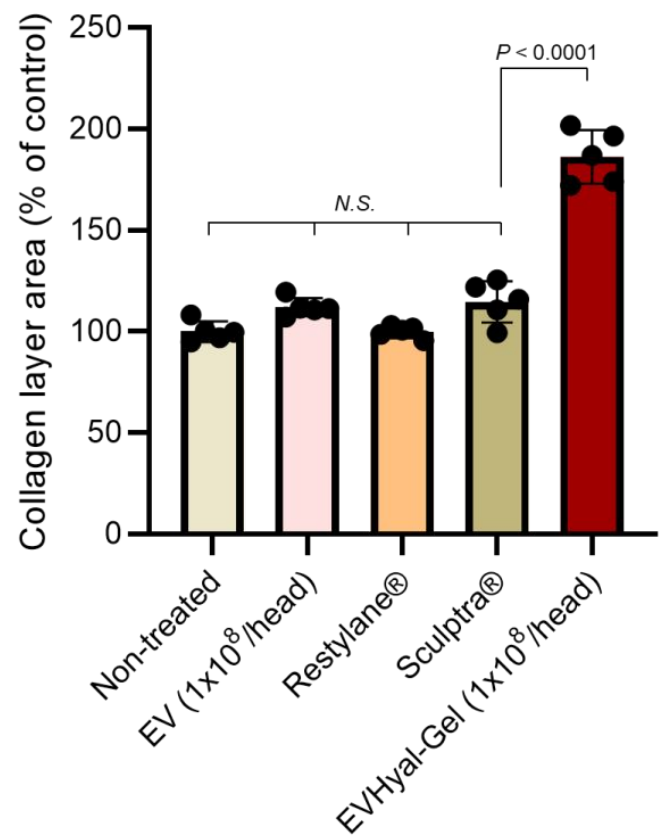

Figure S10. In vivo collagen generation efficacy of EVHyal-Gels 24 weeks after administration.

(a) Masson's trichrome staining images of skin layer of SKH-1 mice. (b) dermis thickness and (c) collagen layer area of SKH-1 mice $(n=5)$. Error bars represent SD. $P$ values were analyzed by the One-way ANOVA. 


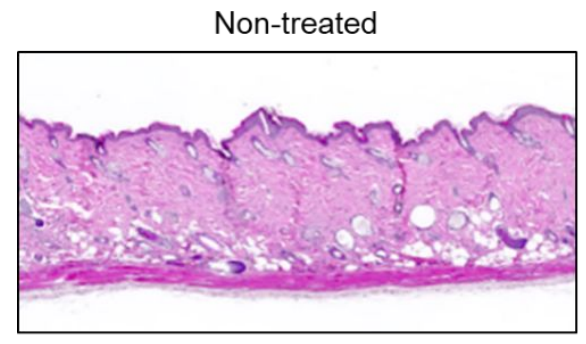

EV $\left(1 \times 10^{8} /\right.$ head $)$

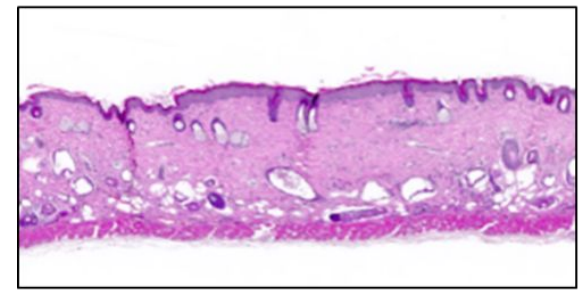

EVHyal-Gel

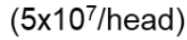

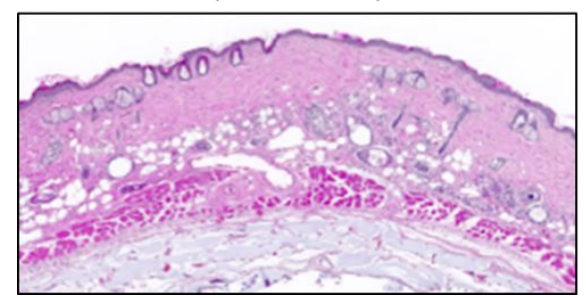

Hyal-Gel

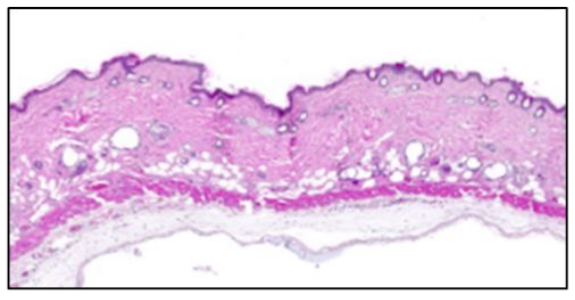

EVHyal-Gel

$\left(1 \times 10^{7} /\right.$ head $)$

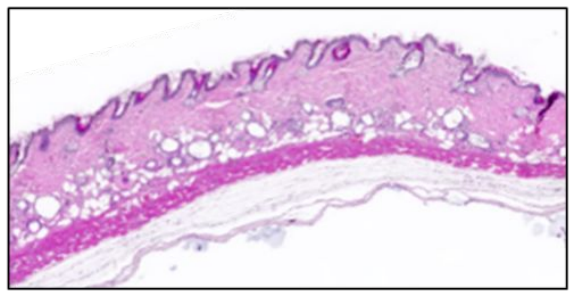

EVHyal-Gel

$\left(1 \times 10^{8} /\right.$ head $)$

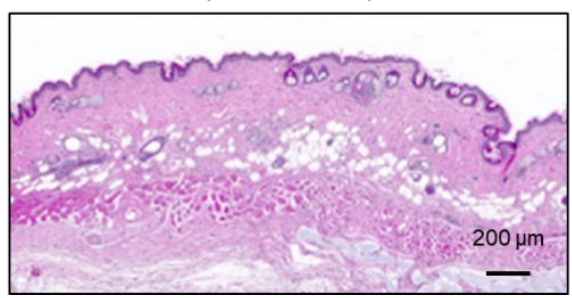

Figure S11. H\&E staining of the skin layers from SKH-1 mice. 


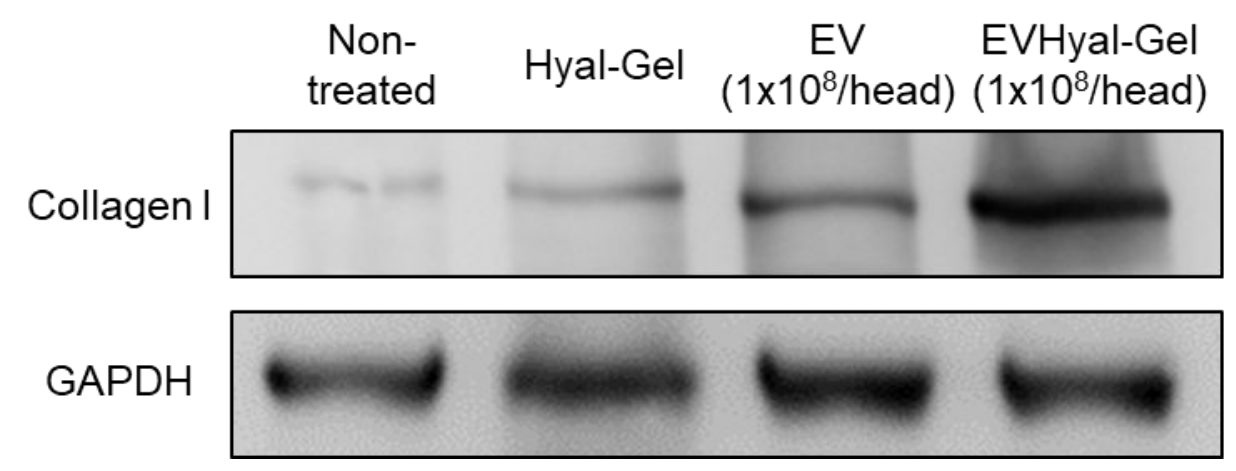

Figure S12. Western blotting analysis of skin tissues of none-, Hyal-Gel-, EV-, or EVHyal-Geltreated mice 4 weeks after a single treatment. 